\title{
Augmented Reality (AR) Enhances the Effectiveness of Lung Expansion in Spinal Surgery Patients -Preliminary Study
}

\author{
Yi-Chun Chen ${ }^{1}$, Man-ling Lin ${ }^{1}$, Hsiau-Yi kao ${ }^{1}$, Shu-Yuan Chou ${ }^{1}$, Shu-Chuan Lin ${ }^{1}$, Yu-Cheng Yao $^{2}$, Ying-Ying \\ Yang $^{3} \&$ Hsiao-Hui Chiu, ${ }^{1,4}$ \\ ${ }^{1}$ Department of Nursing, Taipei Veterans General Hospital, Taipei, Taiwan \\ ${ }^{2}$ Department of Orthopedics, Taipei Veterans General Hospital \\ ${ }^{3}$ Department of Medical Education, Taipei Veterans General Hospital \\ ${ }^{4}$ Department of Nursing, National Taipei University of Nursing and Health Sciences, Taipei, Taiwan \\ Correspondence: Hsiao-Hui Chiu, Department of Nursing, Taipei Veterans General Hospital, Taipei, Taiwan. Tel: \\ 886-2-2871-2121-2398.
}

Received: May 15, 2021

Accepted: June 28, 2021

Online Published: July 8, 2021

doi:10.20849/ijsn.v6i3.903

URL: https://doi.org/10.20849/ijsn.v6i3.903

\begin{abstract}
Background: After spinal surgery, patients often have changes in respiratory system due to general anesthesia. Preoperative respiratory rehabilitation and respiratory muscle training are found to be effective in reducing the postoperative pulmonary complications.
\end{abstract}

Aim: Comparing the differences in the effects of postoperative lung expansion in patients with spinal surgery by using the conventional paper-based and the application of augmented reality (AR) health education methods, and understanding the acceptance of the use of AR by clinical nursing staff.

Subject and methods: The quasi experiment was adopted; the control group was paper-based conventional health education and the experimental group was AR health education. The Trifflow breathing exercise was taught one day before operation. The frequency of exercise was 5-10 minutes each time and four times a day. The exercise was started from the day before operation and was continued until being discharged from the hospital. The pulmonary capacities were measured one day before the operation and on the day of leaving the hospital. Twenty people were recruited in both groups. There were 20 nursing staff participated in this study in total. The acceptance level of using AR was surveyed by using self-administered structured questionnaire.

Result: In the experimental group, females were accounted for $65 \%, 55 \%$ of them were under 64 years old, and $30 \%$ of them with primary education level; in the control group, $85 \%$ of them were females, $70 \%$ of them were over 65 years old, and $30 \%$ with primary education level. The vital capacities measured at the time of discharge comparing with that before the operation were increased in both group, which reached a statistical difference $(\mathrm{p}=0.001)$. However, there was no significantly statistical difference between different groups. In terms of AR recognition by nursing staff: $75.0 \%$ thought that "the current health education tools are not enough", $90 \%$ agreed that "acceptance of AR by patient and family", $75 \%$ agreed that "the AR used in this health education process is convenient", "the use of AR in this health education process is interactive", and "AR health education makes the whole health education process more interesting". Seventy percent agreed that "I have enough relevant resources to use AR health education".

Conclusion: Both traditional and AR health education models can improve the pulmonary function of patients, and there were significantly statistical differences. However, nursing staff felt that the current health education tools were not enough and thought that AR was interactive, interesting and convenient.

Recommendation: The AR medical education has the advantages of interactive games and instant feedback. It can be utilized in clinical services to provide nurses with different models of health education.

Keywords: augmented reality, spinal surgery patients, lung expansion 


\section{Introduction}

\subsection{Spinal Surgery and Pulmonary Complications}

After spinal surgery, patients often have changes in respiratory system caused by the general anesthesia and factors such as the reduction in lung volume, respiratory muscle function changes and insufficient lung expansion caused by postoperative pain. The incidence of postoperative pulmonary complications is $1-23 \%$ (Miskovic \& Lumb, 2017). The most common pulmonary complications include respiratory infection, pneumonia, respiratory failure, pleural effusion, atelectasis, aspiration pneumonia, acute respiratory distress syndrome, pulmonary edema, pulmonary thromboembolism, exacerbation of pre-existing lung disease, pneumothorax, prolonged use of ventilator (Jammer et al., 2015). Once the lung complication occurs, it will seriously affect the patient's prognosis, increase the number of days in hospital, increase medical expenses, and prolong surgical recovery, resulting in up to $14 \%-30 \%$ of patients stay in hospital and 30-day mortality (Miskovic \& Lumb, 2017).

There are many risk factors which can cause postoperative pulmonary have been proposed have be proposed, including age of patient, anesthesia risk level, preoperative lung disease, degree of weakness (functional dependence), chronic disease, weight, smoking, type of surgery, method of anesthesia and anesthetic, etc. The surgery related risk factors include long-duration surgery, long-segment spinal surgery, more bleeding during surgery, revision spinal surgery, scoliosis correction surgery, etc. (Wulff et al., 2020). Many of these risk factors can be corrected before surgery to reduce postoperative pulmonary complications. Preoperative respiratory rehabilitation and respiratory muscle training have been found to be effective in reducing postoperative pulmonary complications (Valkenet et al., 2011).

Preoperative breathing training program mainly includes chest expansion, diaphragmatic breathing, breathing muscles (muscles of expiration, muscles of inspiration, diaphragm muscles) training and the use of incentive spirometer (Trifflow). The traditional training method is to train the patients through one-on-one teaching for one to several times. Self-training is usually unsupervised, and the training frequency and effectiveness are difficult to control.

\subsection{Augmented Reality (AR)}

Augmented reality has been used in rehabilitation applications for many diseases in recent years, for example, the application of post-stroke rehabilitation can assist traditional rehabilitation methods to increase the recovery of upper limb motor function (Kim et al., 2020). The application in the respiratory rehabilitation for the patients with chronic respiratory diseases (such as chronic obstructive pulmonary disease or asthma) can enhance the patient's exercise tolerance, blood oxygen saturation, dyspnea episodes and is entertainment. It is also helpful to improve patient compliance comparing with traditional rehabilitation methods. After six weeks of starting AR or VR rehabilitation, 42\%-96\% of the patients maintain compliance (Condon, Lam, Mosley, \& Gough, 2020). Other reported that the compliance of patient preoperative training was 16\% (Levett, Edwards, Grocott, \& Mythen, 2016). The applications in exercise training for elderly patients can help increase exercise stability and reduce the risk of falls (Ku et al., 2019). The application in orthopedic artificial joint replacement and post-surgery patients with fracture, it has been found to have a comparable effect comparing with the face-to-face rehabilitation. The patient's pain, range of motion, and overall functions has been significantly improved. Moreover, it can reduce the time of transportation to the hospital, expense, and length of stay in hospital, etc. (Berton et al., 2020).

LaPiana (LaPiana et al., 2020) used AR for upper-limb strength exercises. Subjects found that using AR was interesting and enjoyable, and believed that the technology could help them achieve the rehabilitation goals. Besides, there was a statistically significant difference. Berton (Berton et al., 2020) believes that although AR technology could reduce the hospitalization time and cost of the patients and increase the number of patients treated at the same time. Besides, the direct and continuous interactions between the patient and the medical staff increase the patient's motivation and improve the compliance for treatment. However, the obstacles need to be overcome including the majority of orthopedic patients are elderly patients, gamification and popularization of remote rehabilitation are limited among elderly patients. These are because using new technologies are not easy for these patients and having poor adaptability to new technologies. Tait (Tait et al., 2020) found that there was no difference between the printed manual and AR children's understating. However, AR had rich interactive games and expressions were more helpful than manuals. Furthermore, supporting the use with corrected feedback, increasing the understanding of the information, easy to read and visually attractive method to achieve the importance of providing information.

The feature of the AR medical app is that users can see the full picture of self-executing muscle exercises from 
vehicles with rear cameras (such as smartphones, tablets, AR smart glasses, etc.). Demonstration of precise movements and voice instructions by the AR medical teacher in the same screen can prevent sports injuries or soreness caused by wrong movements. The cardiopulmonary exercise is set in the AR medical teaching app which is expected to increase the pulmonary function of the user.

The AR used in this study guided the preoperative breathing exercises for patients undergoing spinal surgery, hoping to achieve better results than traditional one-on-one guidance through medical technology innovation.

\subsection{Operation Definitions}

Experimental group (AR): AR app was used to teach the use of breathing exercises (Trifflow). Users could see the full picture of self-executing breathing exercises through a vehicle with a rear camera such as smartphone. In this study, AR medical teachers could prompt instant voice reminders during the use of the app and gave users surprise encouragement after completing each AR training. This encouragement could be converted into energy for the five-stage growth of AR medical teachers.

Control group (Routine care): traditional health education leaflet was used to teach the use of breathing exercises (Trifflow).

\section{Aim of the Study}

The aims of this study were to:

(1) Compare the differences in vital capacity before and after the operation of patients using conventional health education and AR health education.

(2) Recognition of using AR by nursing staff.

\section{Research Hypothesis}

The research hypothesis is that the vital capacity of patients with AR health education is better than conventional health education $(\mathrm{p}<0.05)$.

\section{Methods and Subject}

\subsection{Research Design}

This was a quasi-experiment, two-group pretest-posttest; convenience sampling was used for subject recruitment.

\subsection{Setting}

The data was collected from the orthopedic wards of a Hospital in northern Taiwan.

\subsection{Participants}

The recruited subjects were patients in the orthopedic ward whose age were 18 years old and above. The recruitment period was from November 8, 2020 to February 5, 2021. Inclusion criteria: patients diagnosed with scoliosis or spondylosis, required to receive long segment (more than four segment) spinal instrumentation and general anesthesia, AR group must have a smartphone. Exclusion criteria: patients who was not diagnosed with scoliosis or spondylosis, not general anesthesia, unable to communicate in Mandarin or Taiwanese, and who was unwilling to accept health education.

\subsection{Methods and Phase of Data Collection}

\subsubsection{Validity and Reliability}

(1) Self-administered structured questionnaire was used for nursing staff, expert validity was used for evaluating the suitability of the content.

(2) Reliability of the researcher: Nursing staff participating in health education received a unified health education training and obtain a unified explanation method. The venue for health education was ward, a private space, to ensure that the health education process would not be disturbed.

\subsubsection{Administrative Approach}

Patients who met the inclusion criteria were assigned to groups after the researcher sought their consent when they were hospitalized. Patients with smartphones were assigned to the AR experimental group. The researcher assisted in setting up the AR app and taught the patients to perform breathing exercises in accordance with the medical teaching app. Subjects who did not have a smartphone were assigned to the control group and regular paper-based health education was provided. The content of breathing exercises included cardiopulmonary exercises (exhalation, diaphragmatic breathing, pursed-lip breathing, chest expansion, upper limbs, etc.), and 
taught patients to use incentive spirometer, Trifflow. The exercise frequency was 5-10 minutes each time, 4 times a day, starting from 1 day before the operation and continuing until discharge from the hospital. The patient's exercise training record sheets were also provided to record the number of exercises, frequency, and the effectiveness of the incentive spirometer. The results of 3 vital capacity measurements between the 2 groups were compared, the measurement time points were 1 day before surgery and the day of discharge from the hospital.

\subsubsection{Ethical Considerations}

The study followed the research ethic and obtained the IRB number 2020-10-010BCF. The study commenced with information the purposed to be impaired by completion of the study.

\subsubsection{Statistics and Data Analysis}

The data were keyed in using Excel with an anonymized encoding process. The statistical software was SPSS 20.0 (IBM SPSS Inc. Chicago Illinois). The basic information was frequency, percentage, Fisher's Exact Test. Generalized estimating equations were used to compare the differences in age, gender, education level and vital capacity between 2 groups.

\section{Results}

\subsection{Baseline Data}

There were 40 people participated in total, $75 \%$ were females. Majority of them were over 65 years old and were accounted for $65.5 \%$. Their education levels were mostly elementary school which accounted for $30 \%$. There were 20 people in the RC group and 20 people in the AR group. Among the RC group, $85 \%$ of them were females, $70 \%$ of them were over 65 years old, $30 \%$ were elementary school educated. For the AR group, $65 \%$ of the subjects were female, $55 \%$ of them were under 64 years old, and elementary school education level was accounted for $30 \%$. There was no statistical difference between the two groups in the distributions of gender, age and education level (Table 1).

Table 1. Basic characteristics of the Patients $(\mathrm{N}=40)$

\begin{tabular}{|c|c|c|c|c|c|}
\hline \multirow[b]{2}{*}{ Variable } & \multicolumn{2}{|c|}{$\mathrm{RC}(\mathrm{n}=20)$} & \multicolumn{2}{|c|}{$\operatorname{AR}(n=20)$} & \multirow[t]{2}{*}{ P-value } \\
\hline & No. & $\%$ & No. & $\%$ & \\
\hline Gender & & & & & 0.55 \\
\hline Males & 3 & 15.0 & 7 & 35.0 & \\
\hline Females & 17 & 85.0 & 13 & 65.0 & \\
\hline Age & & & & & 0.11 \\
\hline 41-64 years old & 6 & 30.0 & 11 & 55.0 & \\
\hline Over 65 years old & 14 & 70.0 & 9 & 45.0 & \\
\hline Education level & & & & & 0.10 \\
\hline Illiteracy & 4 & 20.0 & 1 & 5.0 & \\
\hline Elementary school & 6 & 30.0 & 6 & 30.0 & \\
\hline Junior high school & 1 & 5.0 & 4 & 20.0 & \\
\hline Senior high school & 5 & 25.0 & 5 & 25.0 & \\
\hline University and higher & 4 & 20.0 & 4 & 20.0 & \\
\hline
\end{tabular}

Note: Fisher's Exact Test

\subsection{Comparison of the Differences in Vital Capacity Between 2 Groups}

There was no statistical difference in vital capacity in different groups by comparing the difference in vital capacity between the two groups. There is no statistical difference in vital capacity in different age groups. However, there was a statistically significant difference in the changes of vital capacity before surgery and discharge from the hospital in this 2 groups $(\mathrm{p}=0.001)$. It showed that with these two health education methods, 
the patient's vital capacity before discharge from the hospital was improved comparing with the one before the operation, but there was no statistical difference between the two groups (Table 2).

Table 2. Comparison of the related risk of vital capacity between two groups $(\mathrm{N}=40)$

\begin{tabular}{llllll}
\hline & Variable & OR & $95 \%$ CI & Wald X2 & p-value \\
\hline Group & RC(ref) & 1 & & & \\
\hline Time point & AR group & 0.629 & $0.15-2.64$ & 0.402 & 0.526 \\
\hline \multirow{4}{*}{ Age } & Pre-operational (ref) & 1 & & & \\
\hline & Post-operational & 6.653 & $2.21-20.05$ & 11.33 & $0.001^{* *}$ \\
\hline
\end{tabular}

Note: Generalized estimating equations; $* * \mathrm{p}<0.01$

\subsection{The Level of Recognition of the Nursing Staff Using AR}

Before teaching nursing staff to use AR health education tool, a questionnaire was conducted for the needs of health education tools towards 20 nursing staff. The average age was 29 years old; the age range was $26-42$ years old, and $80 \%$ of them were females. For nursing staff, $80.0 \%$ of them thought that the need of health education was "the incorrect breathing exercise of patients", $75.0 \%$ of them agreed that "current health education tools are not enough". Nevertheless, only $45 \%$ of them had "has confidence in using AR to assist health education" (Table 3). These show that nursing staff believe that health education of patients' breathing exercises is needed and hope to have new health education tools. However, they are not confident in the use of AR.

Table 3. The needs of health education tools for nursing staff $(\mathrm{N}=20)$

\begin{tabular}{|c|c|c|c|c|c|c|}
\hline Variable & Stro & $\mathrm{ee}+\mathrm{A}$ & $\mathrm{Neu}$ & & Disa & ongly disagree \\
\hline & No. & $\%$ & No. & $\%$ & No. & $\%$ \\
\hline $\begin{array}{l}\text { 1. You feel that the current health } \\
\text { education tools are not enough }\end{array}$ & 15 & 75.0 & 5 & 25.0 & 0 & 0.0 \\
\hline $\begin{array}{l}\text { 2. You feel that the breathing exercises of } \\
\text { clinical patients are incorrect }\end{array}$ & 16 & 80.0 & 3 & 15.0 & 1 & 2.5 \\
\hline $\begin{array}{l}\text { 3. You fully understand the content of this } \\
\text { health education theme }\end{array}$ & 14 & 70.0 & 6 & 30.0 & 0 & 0.0 \\
\hline $\begin{array}{l}\text { 4. You have the capability to use AR } \\
\text { assisting health education and explain the } \\
\text { health education theme to patients (or } \\
\text { family members) }\end{array}$ & 13 & 65.0 & 7 & 35.0 & 0 & 0.0 \\
\hline $\begin{array}{l}\text { 5. You have confidence in using AR to } \\
\text { assist health education }\end{array}$ & 9 & 45.0 & 10 & 50.0 & 1 & 2.5 \\
\hline
\end{tabular}

After the recruitment was closed, the level of recognition of nurses using AR was investigated again. In terms of tool recognition, more than $60 \%$ of staff had a positive attitude towards AR, according to the order was convenience $(75 \%)$, interestingness $(75 \%)$, interactivity (75\%),visual and auditory effects $(70 \%)$, repeatability (70\%), good method (65\%), effectiveness (60\%). In terms of patient benefits, $90 \%$ of them believed that the patient accepted AR, but only $40 \%$ of them believed that AR could quickly perform health education. More than $65 \%$ of them agreed that they had the knowledge to use AR. Over $50 \%$ thought that they had operational skills. For the willingness of using AR, $75 \%$ of them thought that AR made health education more interesting, but only $45 \%$ believed that the use of AR was effective. In summary, it shows that nursing staff agreed with the advantages of AR tools (more than $60 \%$ ), and patient acceptance was high (90\%). Fifty percent of nursing staff had the relevant knowledge and skills to use AR, and 55\% of them believed that AR learning methods could 
reduce learning anxiety of patient. However, only $40 \%$ believed that AR could increase the rapidity of health education.

Table 4. The level of recognition of using AR health education tool by nursing staff $(\mathrm{N}=20)$

\begin{tabular}{llllll}
\hline Variable & $\begin{array}{l}\text { Strongly agree } \\
+ \text { Agree }\end{array}$ & Neutral & \multicolumn{2}{l}{$\begin{array}{l}\text { Disagree }+ \\
\text { Strongly disagree }\end{array}$} \\
\hline & No. & $\%$ & No. & $\%$ & No. $\%$ \\
\hline
\end{tabular}

The $\quad$ 1. I agree that the AR used in this

recognition health education process is

of the tool convenient 15

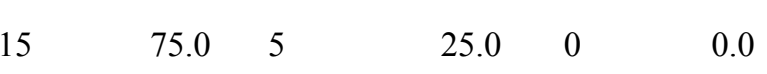

2. I agree that the AR used in this health education process is interactive

3. I agree that the AR used in this health education process has good sound and light effects 14

$\begin{array}{llllll}15 & 75.0 & 4 & 20.0 & 1 & 2.5\end{array}$

4. I agree that the AR used in this health education process can be used repeatedly 14

5. I agree that the AR used in this health education process can achieve effective health education 12

$\begin{array}{llllll}14 & 70.0 & 6 & 30.0 & 0 & 0.0\end{array}$

\begin{tabular}{|c|c|c|c|c|c|c|}
\hline & achieve effective health education 12 & 60.0 & 7 & 35.0 & 1 & 2.5 \\
\hline \multirow[t]{3}{*}{$\begin{array}{l}\text { Patient } \\
\text { benefits }\end{array}$} & $\begin{array}{l}\text { 1. I agree that patient's learning } \\
\text { anxiety can be reduced through AR } 11\end{array}$ & 55.0 & 6 & 30.0 & 3 & 7.5 \\
\hline & $\begin{array}{l}\text { 2. The use of AR health education } \\
\text { can perform the health education } \\
\text { more quickly }\end{array}$ & 40.0 & 12 & 60.0 & 0 & 0.0 \\
\hline & $\begin{array}{l}\text { 3. The acceptance of AR by } \\
\text { patients }\end{array}$ & 90.0 & 2 & 10.0 & 0 & 0.0 \\
\hline \multirow{2}{*}{ Knowledge } & $\begin{array}{l}\text { 1. I have enough related resource to } \\
\text { use AR health education }\end{array}$ & 70.0 & 6 & 30.0 & 0 & 0.0 \\
\hline & $\begin{array}{l}\text { 2. I have enough related knowledge } \\
\text { to use AR health education }\end{array}$ & 65.0 & 7 & 35.0 & 0 & 0.0 \\
\hline \multirow[t]{2}{*}{ Skills } & $\begin{array}{l}\text { 1. It is easy for me to familiarize } \\
\text { with AR health education }\end{array}$ & 65.0 & 6 & 30.0 & 1 & 2.5 \\
\hline & $\begin{array}{l}\text { 2. I think that performing health } \\
\text { education through AR is easy } 10\end{array}$ & 50.0 & 8 & 40.0 & 2 & 5.0 \\
\hline \multirow[t]{6}{*}{ Attitude } & $\begin{array}{l}\text { 1. The use of AR health education } \\
\text { is a good idea }\end{array}$ & 65.0 & 7 & 35.0 & 0 & 0.0 \\
\hline & $\begin{array}{l}\text { 2. AR health education makes the } \\
\text { whole health education process } \\
\text { more interesting }\end{array}$ & 75.0 & 5 & 25.0 & 0 & 0.0 \\
\hline & 3. I like using AR health education 13 & 65.0 & 6 & 30.0 & 1 & 2.5 \\
\hline & $\begin{array}{l}\text { 4. I feel anxious about using AR } \\
\text { health education }\end{array}$ & 25.0 & 14 & 70.0 & 1 & 2.5 \\
\hline & $\begin{array}{l}\text { 5. I am hesitant whether to use AR } \\
\text { health education or not }\end{array}$ & 45.0 & 14 & 70.0 & 1 & 2.5 \\
\hline & $\begin{array}{l}\text { 6. I feel that AR health education is } \\
\text { useful }\end{array}$ & 45.0 & 11 & 55.0 & 0 & 0.0 \\
\hline
\end{tabular}




\section{Discussion}

Wulff (2020) believes that the probability of having pulmonary complications causing by spinal surgery is high. The method of anesthesia and age are both the risk factors. The preoperative breathing rehabilitation and breathing muscle training were found to be effective for reducing the postoperative pulmonary complications. The recruited subjects of this study were patients with scoliosis or spondylosis, required to receive long segment (more than four segments) spinal instrumentation and general anesthesia. Most of them were over 65 years old $(65.5 \%)$. They were the high-risk patients of postoperative pulmonary complications. These were similar to the findings of the researcher. In this study, the vital capacity before discharge from the hospital was improved comparing with the one before surgery after lung breathing training and had statistically significant difference. This result is similar to the research results found by Wulff (2020) and Valkenet (2011). It is effective to decrease the postoperative pulmonary complications through the breathing muscle training.

In this study, it was found that nursing staff agreed that the features of AR were convenience, interestingness, interactivity, visual and auditory effect, high patient acceptance and can achieve effective health effect. The results were similar to the results found by LaPiana (2020), Berton (2020), Tait (2020) and other researchers that the tool was interesting and high interactive in AR clinical applications, and more attractive than conventional paper-based method. The age of patients in this study was relatively high and mostly was over 65 years old. However, smartphone was required for the AR group and willingness of learning AR operation mode, and hence the patients were mostly 41-64 years old (55\%). Berton (2020) also had similar findings. The patients in orthopedics were mostly elderly. It was relatively difficult for elders to learn new technology. Only $40 \%$ of the nursing staff agreed that AR could make the performance of health education more quickly. These indicated that promoting AR in clinical field might face difficulties due to the age of the patients.

Regarding the readiness of nursing staff using AR, only $40 \%$ of nursing staff were confident to use AR before providing AR training. After the completion of the AR training, $65 \%$ of them believed that they had enough related knowledge, $65 \%$ liked to use AR health education. However, $45 \%$ of them hesitated whether to use AR health education. It indicates that the abilities and skills of nursing staff are still needed to be improved for the future promotion of AR health education model, overcoming the obstacles such as the abilities and willingness for elderly patients to accept new technology, having the smart devices for AR and so on.

$\mathrm{Ku}$ et al. (2019) found that 3D-ARS systems can more effectively improve the balance of older people, with statistically significant differences, because the screen provides action screen, elder people can effectively achieve learning by watching screen action, our founds were similar to this study. Tang et al. (2020) reviewed 100,807 articles and found that AR is growing rapidly in medical education, but more clinical evidence and experimental research were needed to confirm its value, and the analysis of results was the direction of subsequent development of our study.

\section{Limitation of the Study}

This study was a pilot experiment. Twenty subjects were recruited in both groups. There was no significant difference in increase of pulmonary function. The number of recruited subjects can be increased in the future and continuing to track the rehabilitation status after returning home from the hospital to confirm the benefits of AR health education in long-term rehabilitation.

\section{Conclusion}

Both traditional and AR health education models could improve the pulmonary function of patients, and there were statistically significant differences. Seventy percent of nursing staff felt that the current health education tools were not enough. Seventy-five percent thought that AR was interactive, interesting and convenient, Ninety percent of them agreed that AR could be accepted by patients, showing the development potential of AR in clinical applications.

\section{Recommendation}

Based on the findings of this study, the recommendations are that the advantages of AR medical education are interactive game and immediate feedbacks. It can be used for clinical service and provide different health education models for medical staffs. The benefit of AR is tracking management of remote self-learning, this is the trend of future development.

\section{References}

Berton, A., Longo, U. G., Candela, V., Fioravanti, S., Giannone, L., Arcangeli, V., ... Denaro, V. (2020). Virtual reality, augmented reality, gamification, and telerehabilitation: psychological impact on orthopedic patients' 
rehabilitation. J Clin Med, 9(8). https://doi.org/10.3390/jcm9082567

Condon, C., Lam, W. T., Mosley, C., \& Gough, S. (2020). A systematic review and meta-analysis of the effectiveness of virtual reality as an exercise intervention for individuals with a respiratory condition. $A d v$ Simul (Lond), 5(1), 33. https://doi.org/10.1186/s41077-020-00151-z

Jammer, I., Wickboldt, N., Sander, M., Smith, A., Schultz, M. J., Pelosi, P., ... Pearse, R. M. (2015). Standards for definitions and use of outcome measures for clinical effectiveness research in perioperative medicine: European Perioperative Clinical Outcome (EPCO) definitions: A statement from the ESA-ESICM joint taskforce on perioperative outcome measures. Eur $J$ Anaesthesiol, 32(2), 88-105. https://doi.org/10.1097/EJA.0000000000000118

Kim, W. S., Cho, S., Ku, J., Kim, Y., Lee, K., Hwang, H. J., .. Paik, N. J. (2020). Clinical application of virtual reality for upper limb motor rehabilitation in stroke: review of technologies and clinical evidence. $J$ Clin Med, 9(10). https://doi.org/10.3390/jcm9103369

Ku, J., Kim, Y. J., Cho, S., Lim, T., Lee, H. S., \& Kang, Y. J. (2019). Three-dimensional augmented reality system for balance and mobility rehabilitation in the elderly: a randomized controlled trial. Cyberpsychol Behav Soc Netw, 22(2), 132-141. https://doi.org/10.1089/cyber.2018.0261

LaPiana, N., Duong, A., Lee, A., Alschitz, L., Silva, R. M. L., Early, J., .. Mourad, P. (2020). Acceptability of a mobile phone-based augmented reality game for rehabilitation of patients with upper limb deficits from stroke: case study. JMIR Rehabil Assist Technol, 7(2), e17822. https://doi.org/10.2196/17822

Levett, D. Z., Edwards, M., Grocott, M., \& Mythen, M. (2016). Preparing the patient for surgery to improve outcomes. Best Pract Res Clin Anaesthesiol, 30(2), 145-157. https://doi.org/10.1016/j.bpa.2016.04.002

Miskovic, A., \& Lumb, A. B. (2017). Postoperative pulmonary complications. Br J Anaesth, 118(3), 317-334. https://doi.org/10.1093/bja/aex002

Tait, A. R., Connally, L., Doshi, A., Johnson, A., Skrzpek, A., Grimes, M., ... Weber, M. (2020). Development and evaluation of an augmented reality education program for pediatric research. J Clin Transl Res, 5(3), 96-101.

Tang, K. S., Cheng, D. L., Mi, E., \& Greenberg, P. B. (2020). Augmented reality in medical education: a systematic review. Canadian Medical Education Journal, 11(1), e81-e96.

Valkenet, K., Van de Port, I. G., Dronkers, J. J., De Vries, W. R., Lindeman, E., \& Backx, F. J. (2011). The effects of preoperative exercise therapy on postoperative outcome: a systematic review. Clin Rehabil, 25(2), 99-111. https://doi.org/10.1177/0269215510380830

Wulff, I., Duah, H. O., Osei Tutu, H., Ofori-Amankwah, G., Yankey, K. P., Owiredu, M. A., ... Boachie-Adjei, O. (2020). Postoperative pulmonary complications in complex pediatric and adult spine deformity: a retrospective review of consecutive patients treated at a single site in West Africa. Global Spine J, 2192568220942482. https://doi.org/10.1177/2192568220942482

\section{Copyrights}

Copyright for this article is retained by the author(s), with first publication rights granted to the journal.

This is an open-access article distributed under the terms and conditions of the Creative Commons Attribution license (http://creativecommons.org/licenses/by/4.0/). 